\title{
APROXIMACIÓN EDUCATIVA ANTE LOS NUEVOS FORMATOS NARRATIVOS
}

\author{
Amando López Valero \\ Universidad de Murcia \\ amandolo@um.es \\ Isabel Jerez Martínez \\ Universidad de Castilla-La Mancha \\ isabel.jerezmartinez@uclm.es \\ Eduardo Encabo Fernández \\ Universidad de Murcia \\ edencabo@um.es
}

\begin{abstract}
RESUMEN / ABSTRACT
El objetivo de este artículo es realizar un planteamiento que atienda a la realidad social y educativa que está aconteciendo en la segunda década del siglo XXI. Somos conscientes de las transformaciones que está sufriendo el texto, sobre todo en el medio por el que se transmite. Este hecho afecta sobremanera a la lectura, ya que, las personas nos enfrentamos a nuevos formatos narrativos que suponen grandes desafíos para el acceso al conocimiento.

En esta contribución llevaremos a cabo un repaso de aquellos medios que conllevan nuevos formatos narrativos y trataremos de identificar su influencia en la formación lectora de las personas. Interrogantes como ¿es preciso que las instituciones educativas y los currículos se adapten a los nuevos tiempos en materia de promoción lectora?, ¿los nuevos formatos narrativos conllevan nuevos valores? o ¿dichos formatos generan formas distintas de ver y comprender la realidad? serán planteados.

Desde el planteamiento del artículo trataremos de responder a dichas cuestiones incardinándolas en un entramado teórico-práctico que tiene que ver con la enseñanza de la lengua y la literatura y con el enfoque crítico de la educación, abogando por el pensamiento crítico y la autonomía en el acceso al conocimiento.
\end{abstract}

Palabras Clave: nuevos formatos narrativos, alfabetización digital, pensamiento creativo, didáctica de la literatura. 
The aim of this article is to propose an argument which acknowledges examine the social and educational reality being developed in the second decade of the twenty-first century. We are aware of the transformations that the text is going through, above all, in the format in which it is transmitted. This fact overwhelmingly affects reading, because people face new narrative formats which entail greater challenges in the access to knowledge. In this contribution we will carry out a review of those media that offer new narrative formats and we will try to identify their influence on the development of the reader. We will examine such questions as: Is it necessary for educational institutions and curricula to adapt to this new era in terms of the promotion of reading? Do these new narrative formats represent new values? Or, Do these new narrative formats generate new ways of seeing and understanding reality?

From the main argument of this article we will try to answer these questions considering a theoretical-practical background which is linked with the teaching of language and literature, and with the critical perspective of education, arguing for critical thinking and autonomy in the access to knowledge.

KEYWORDS: New narrative formats, digital literacy, creative thinking, literature didactics.

\section{INTRODUCCIÓN}

Esta segunda década del siglo XXI está poniendo de manifiesto que la eclosión digital está condicionando los comportamientos y, sobre todo, los modos de pensar de las personas. La filosofía humanista se encuentra en segundo plano y la tendencia tiene que ver con la inmediatez y lo satisfactorio. Es un hecho tangible que la modernidad líquida definida por Bauman (2003) es una constante en la cotidianeidad y, los conceptos que en torno a la digitalidad fueron acuñados por Jenkins (2008), tales como residentes o nativos digitales, son precisos para poder describir los comportamientos de las personas. Por ello, es preciso reformular cuestiones educativas y sociales que conciernen a la lectura para conocer realmente cuál es el concepto que se está tratando en la sociedad actual y, ante todo, para entender qué papel va a tener esa lectura en la formación y desarrollo de la persona.

Definir correctamente qué entendemos por lectura va a conllevar que escudriñemos el entorno social y apreciemos que el texto ya no se presenta en un formato único sino que fluctúa mediante distintas manifestaciones que ya no se limitan a la presentación física; al contrario, pueden formar parte de entornos virtuales o estar encriptadas en un formato audiovisual. A este respecto, la tradición no permite asumir de manera natural estas nuevas manifestaciones y existe cierta resistencia a reconocer que esa interacción con medios audiovisuales o digitales pueda ser denominada lectura. 
Como hemos indicado, además de la acotación del concepto lector, nos interesa sobremanera la interacción que se produce entre las personas y los textos, deseando por nuestra parte que la misma esté orientada a la generación de conocimiento desde la perspectiva crítica. Por ello, mediante el recorrido que efectuaremos a través de los diferentes epígrafes de este artículo queremos vincular los dos aspectos clave que hemos reseñado, la posible nueva concepción lectora y la vinculación de la misma a una perspectiva formativa que procure articular y promocionar el pensamiento crítico.

\section{CONCEPTO DE LECTURA EN EL SIGLO XXI. CONDICIONANTES POSTMODERNISTAS}

La visión romántica e idealista de la lectura parece no tener cabida en estas décadas de siglo que nos contemplan. La interpretación del acto lector como algo placentero que conlleva un aprendizaje y que evoca al ser humano contemplando un ejemplar físico de un libro rodeado de paz e inmerso en un proceso de erudición, no parece el referente a tener en cuenta cuando se trata de observar qué entendemos por lectura. Siguiendo a Giddens (1993), los ejes funcionales de la llamada modernidad transitan por presupuestos como la vigilancia, el industrialismo o la acumulación de capital. Estos, condicionan la visión de la lectura, ya que lo concerniente a la misma se rige por dichos elementos.

Las editoriales determinan el ritmo de producción de los libros y, debido a las premisas económicas que se amparan en los resultados económicos, determinan qué obras son susceptibles de ser consumidas. Es importante reflexionar sobre la semántica de los términos, ya que, usar el verbo consumir en lugar del verbo leer puede ser una característica del siglo XXI. Conjugar el primero que hemos mencionado se vincula estrechamente a la industria y al capitalismo, ya que se considera el libro, o en su caso el formato en el que se presente el texto, como un objeto que debe ser consumido por los usuarios. La persona lectora también puede perder su denominación como lectora y pasar a ser simplemente usuaria que consume un producto. Desde esa óptica, no podemos considerar la lectura como algo que tenga un fin formativo sino como una parte de un engranaje comercial que cumple una función en el marco de referencia que suponen los mercados.

El otro eje que se ha citado, la vigilancia, tendría su transposición en el contenido de los libros que se proponen a las personas para leer y, sin 
duda, se relaciona con el mercado, ya que hay una conexión de intereses. De alguna manera, los contenidos editoriales, sobre todo en los textos que disfrutan de éxito comercial, incluyen temáticas y cuestiones que influyen en el pensamiento de los lectores que tienen acceso a ellas. Por poner un ejemplo, la proliferación de novelas juveniles distópicas a partir del 11 de septiembre de 2001 no parece algo casual sino que puede tener que ver con la conformación de un determinado tipo de pensamiento y la conexión que se produce entre el mismo y el concepto de vigilancia. Es decir, estamos indicando que la lectura se convierte en un instrumento de control y de conformación o cambio de pensamiento de aquellas personas a las que se dirigen unos determinados libros. En este caso probablemente no tendríamos que aludir a libros sino a productos mediáticos que poseerían un objetivo concreto.

Así pues, para acotar el concepto de lectura hemos de tener en cuenta estos condicionantes y plantearnos qué amplitud va a poseer dicha noción. Como bien hemos expresado, la mirada romántica y nostálgica del lector debe dar paso a la constatación de una realidad y es que el dinamismo y la celeridad social exigen que los espacios lectores varíen, modificándose de ese modo la percepción acerca de lo que es una persona lectora. Al cambiar los espacios para leer y también los formatos, lo que permanece es el contenido textual. Ahora bien, en nuestra aproximación conceptual debemos tener claro si se puede deslindar el contenido de la forma; $y$, cómo afecta esta última a la recepción y comprensión de los textos. La mutación de las prácticas lectoras es una evidencia (Martos y Campos 2013) y la cantidad de modalidades de lectura es ingente. Por ello, ¿debemos considerar que existen a su vez múltiples tipos de personas lectoras? Obviamente, la respuesta debe ser afirmativa y, desde nuestro punto de vista, la apertura de miras es una de las claves para comprender qué sucede con la lectura en pleno siglo XXI. Son las distintas modalidades las que contribuyen a entender cómo y qué se lee en esta época. Contextualizar los actos lectores oteando cuáles son las condiciones sociales nos proporciona una forma más coherente de saber qué es la lectura en estos tiempos y, sobre todo, qué opciones hay para contemplarla desde el ámbito educativo con vistas a la formación de personas. A lo largo de los siguientes apartados queremos ir perfilando este aporte que con respecto del concepto hemos comenzado a realizar. 


\section{2. ¿ESTÉTICA DE LA RECEPCIÓN PARA ENTENDER EL CONCEPTO DE LECTURA?}

Tras lo reseñado previamente, queremos reseñar que, desde nuestro punto de vista, una de las claves para entender la lectura en este siglo XXI va a residir en las personas. Las modificaciones que atienden a los cambios sociales y que podrían definir el acto lector no se sostienen sin tener en cuenta las conductas o actuaciones que se derivan de la cotidianeidad de los seres humanos. Como nos indican Jauss (1977) o Iser (1987), el texto, en sus diferentes manifestaciones, requiere de una interacción con la persona que hace uso del mismo; $y$, es esta última la que dota de sentido a los contenidos que presentan dichas lecturas. Desde la teoría de la estética de la recepción uno de los aspectos clave reside en el bagaje experiencial que tiene la persona que va a interactuar con el texto. En este sentido, lo apuntamos como uno de los elementos esenciales que va a condicionar nuestra visión de la lectura.

Las personas que habitan la sociedad del siglo XXI tienen un perfil sensiblemente distinto de las del siglo pasado. La transformación de las condiciones de vida a la par que la influencia de sistemas educativos diferentes, unidos a la digitalización presente en la cultura que trasciende a dichos seres, ha propiciado que hallemos personas con una forma de pensar distinta de las que habitaban en el siglo precedente. También han variado las maneras de expresión que poseen estos seres humanos, por lo que todo ello ha contribuido a que no se pueda conceptualizar la lectura como antaño se hacía.

El factor digital, paulatinamente, va modificando las formas de comportamiento de los habitantes de las sociedades y lo hace tanto en lo concerniente a la forma como al contenido. La forma de acometer el texto no es la misma si la costumbre está referida al manejo de libros físicos que si se está experimentando el acto lector utilizando dispositivos digitales. La fijación de la vista es distinta y los puntos de atención son diferentes. De igual manera, la concentración varía y, como nos indica Christensen (2013), el formato papel tiene unas mejores implicaciones para la lectura que la lectura en pantalla, sobre todo en lo que tiene que ver con la concentración o fijación de ideas. Aunque esto suceda, socialmente no se realiza una imposición relativa a qué formato utilizar sino que los usuarios son libres para determinar qué formato usar. A modo de ejemplo, y centrados en el ámbito escolar, en la investigación llevada a cabo por Minelli et al. (2014), estas estudiosas reflejan que, pese a la motivación que puede conllevar el libro de texto en formato electrónico, todavía existen carencias que no permiten que sea igualado con el formato 
físico. Todos estos aspectos van moldeando la forma de acometer un texto por parte de las nuevas generaciones y aconsejan reconsiderar qué supone leer en el siglo en el que nos encontramos.

Como hemos señalado, esa irrupción digital, que lleva asociada el factor de la inmediatez, también supone una modificación en los usos de la lengua $\mathrm{y}$, por ende, en las expectativas que posee la persona lectora. Esto es, si la utilización de lo lingüístico es más acelerada y precisa de un planteamiento menos retórico y más práctico, la persona lectora demandará este tipo de textos, teniendo una menor preferencia por documentos $u$ obras que hagan uso de un estilo más elaborado u ornamental. Este hecho va a provocar que, en nuestra reflexión, tengamos que reconsiderar determinados textos que según la crítica o los académicos no consideraríamos lectura pero que, siguiendo estas directrices sociales, probablemente puedan ser tildados dentro de la acción lectora.

Así pues, pensamos que la estética de la recepción es esencial como paradigma que permite apreciar las experiencias de la persona a la hora de acometer la lectura de un texto y, sobre todo, de interaccionar con él. Este nuevo perfil de persona que se relaciona con las manifestaciones sociales del siglo XXI es la clave para poder entender que el concepto de lectura ha evolucionado y ha superado la percepción precedente que hubiese del mismo.

\section{PENSAMIENTO LATERAL O DIVERGENTE, ¿UNA NECESIDAD?}

El cambio social que hemos referido anteriormente también se caracteriza, en ocasiones, por la presencia de un pensamiento único que conduce inexorablemente a la homogeneidad. Los medios de comunicación de masas, inevitablemente, proporcionan mensajes únicos que se dirigen a la colectividad, provocando que el pensamiento converja. Siendo estos pensamientos similares, es lógico que la interpretación que se hace de textos o de la literatura sea muy similar. Esta situación es paradójica si la contrastamos con el discurso políticamente correcto que concierne a la diversidad. En todos los casos sociales hallamos el ensalzamiento de lo diverso, de la riqueza que existe en ser distinto, en opinar de otra manera pero, en la práctica los mensajes tienen que ver más con la convergencia.

Por esa razón, planteamos si el pensamiento lateral o la divergencia se convierten en una necesidad educativa, si al formar a las personas tenemos 
que incidir en estas dimensiones o conformarnos con la homogeneidad. De Bono (2006) indica que este concepto tiene que ver con la producción de ideas que estén fuera del patrón de pensamiento habitual. Aplicado a la lectura implicaría intentar que la percepción e interpretación del contenido de los libros o textos usados no fuese algo estándar sino que las personas tengan la libertad para explorar diferentes entendimientos, partiendo, como hemos expresado en el apartado anterior, de sus experiencias personales y culturales. Estas, como algo particular, pueden definir universos interpretativos que difieran de una persona a otra. Además, habría que incluir en esta idea, la promoción de la lectura, ya que, dicha acción motiva el acercamiento a multitud de libros, ampliando el conocimiento sobre temas, problemas y valores que se pueden hallar en los textos reales o de ficción y conectándolos con las vivencias particulares que cada persona posee.

Enlazada con estas ideas se encuentra la noción de lectura crítica. Esta sería una prolongación de ese pensamiento crítico o lateral y vendría definida como Encabo (2013) nos indica, de esta manera:

aquella en la que el lector es capaz de interactuar con el texto, de poner en relación con el mismo sus conocimientos previos y los actuales; y además, es capaz de reflexionar y debatir sobre el contenido que ha recibido, valorándolo y juzgándolo con la finalidad de incorporarlo o no a su acervo de conocimiento (371).

Nos gustaría resaltar de dicha definición el hecho referido a que la persona tiene libertad para decidir qué hacer con los nuevos contenidos que adquiere mediante la lectura. Es decir, la acción crítica entronca con la capacidad para decidir qué hacer con las nuevas informaciones o contenidos que uno recibe de la lectura y, sobre todo, para determinar si son o no significativas para incorporarlas al bagaje de experiencias culturales y de conocimiento que la persona va poseyendo a lo largo de su vida.

Como se ha mencionado, en la época mediática la convergencia cada vez es más acusada, ya que se poseen medios de comunicación de masas que pueden posibilitar que una determinada información o contenido pueda llegar a multitud de personas, sin que, en ocasiones, el mismo sea filtrado o analizado. Por ello, desde nuestro punto de vista, coincidimos con Robinson (2009) en que existe la necesidad de que el pensamiento lateral y la lectura crítica sean estimulados en las personas, para que tengan la posibilidad de ir más allá de esas ideas que les son transmitidas; $y$, ante todo, para que puedan 
contribuir a la comunidad de la que forman parte, aportando impresiones y opiniones que despierten la curiosidad del resto de personas con las que se comunican. La lectura supone pues implicación personal y capacidad crítica, si se convierte en algo mecánico, forzado y que forma parte de una rutina social, caerá en desuso y lo que es más relevante, no tendrá ningún valor para las personas que la utilizan.

Con estos pilares que estamos generando en este artículo, es decir, un contexto sociocultural que tiene al postmodernismo como seña de identidad, la referencia de la estética de la recepción como teoría literaria que sustenta la idea de lectura y la lectura crítica junto con el pensamiento lateral como objetivo de la acción lectora, deseamos en la siguiente sección definir qué es la lectura, combinando ya las novedades referidas a formatos que podemos hallar en nuestra vida cotidiana.

\section{NUEVOS FORMATOS NARRATIVOS. ¿A QUÉ LLAMAMOS LEER?}

Ya lo hemos expresado a lo largo de muchas de las líneas precedentes, la idea de una persona lectora estática, tranquila, en un atril, con un libro físico, es una visión romántica, que se sigue produciendo en nuestros días pero que no es lo habitual, debido a las condiciones sociales a las que la persona se enfrenta en su cotidianeidad. Partimos de concepciones clásicas como la de Solé (1992) en las que la lectura no puede entenderse como un acto de mera descodificación, en el que atendemos a un código y simplemente le vamos dando un determinado valor en función de los componentes del mismo. La presencia de las experiencias personales y el dotar a ese texto de un sentido en función de nuestras expectativas tiene un papel esencial en el acto lector. Ahora bien, nuestras nuevas experiencias transitan por un mundo audiovisual que en las dos últimas décadas se ha expandido de una manera significativa. Formatos como el que tiene que ver con el cine, con los videojuegos, con los canales de internet o incluso con la música, han potenciado su presencia social y han incrementado su complejidad en lo que concierne a contenidos, convirtiéndose en potentes industrias (volvemos a señalar en este punto tanto la industria como el capitalismo como señas de la postmodernidad) que se vinculan al día a día de las personas.

Todos estos formatos que hemos indicado albergan en su seno multitud de textos que contienen distinta información. El usuario o persona lectora se 
relaciona constantemente con ellos y la pregunta que cabría plantearse es: ¿se está realizando un acto de lectura en esa interacción? $\mathrm{O}$, ¿no podemos elevar a la categoría de lectura esas situaciones? Lógicamente, las posturas más tradicionales defenderán que al no haber un texto físico, diseñado o redactado al efecto, no se pueden considerar esos actos puntuales de interacción con medios, principalmente audiovisuales, como una acción lectora. Pero, si atendemos a las características de la lectura que tienen que ver con la estimulación del pensamiento, con la activación de ideas y con la identificación de un texto (independientemente de que se presente de manera física o escrita), debemos cuestionarnos estas situaciones. Limitar el concepto lector a la presencia de textos escritos puede no estar acorde con los tiempos actuales y, como hemos señalado, tal vez, esté coartando las posibilidades de la lectura en lo que respecta a motivación o conocimiento que se genere a partir de la misma. Estamos de acuerdo con Lluch (2010) en que los nuevos tiempos y los nuevos formatos han conllevado la presencia de un nuevo lector.

Obviamente no todos los formatos aludidos poseen siempre textos interesantes o con contenido susceptible de análisis para poder considerarlos como un acto lector. La liviandad de determinados contenidos cinematográficos o de videojuegos no permite advertir que la persona cuando es usuaria de dichos formatos esté poniendo en relación sus experiencias culturales previas en forma de textos y lecturas con el posible texto que se incluye en el formato que se le oferta. Pero, otras veces, la complejidad de las producciones nos hace pensar que existe un texto perfectamente identificable, presentado en otro formato, y la persona está haciendo un esfuerzo que va más allá de la mera descodificación.

La competencia digital y los nuevos formatos narrativos pueden tener una vinculación, no estando ninguna de las dos al margen de la promoción de la lectura (López Valero et al. 2011). Estos formatos, ya tengan que ver con el cine, las series de televisión o los videojuegos, van a permitir que el residente o nativo digital halle recursos para desarrollar su lectura crítica sin perjuicio de sentirse bien o mal por utilizar un medio que no es el libro físico. Es preciso pues que se tome conciencia acerca de que lo importante es el texto y el contenido que este conlleva y no tanto la forma en la que se ofrezca ese texto (con ello, no estamos denostando la forma en la que se presenta el contenido sino que tratamos de incidir en la pluralidad textual y en las nuevas opciones que se le ofrecen a la persona en el siglo XXI).

Queremos afirmar pues que, desde nuestra óptica, enriquecemos el concepto lector, yendo más allá de la presencia física del libro y, lo ampliamos, considerando 
otros formatos narrativos. En las siguientes secciones comentaremos algunos fenómenos de la sociedad digital que se asocian a esta situación y es nuestra intención reseñar la repercusión que los mismos tienen en la formación de personas, es decir, en el ámbito educativo.

\section{LECTURA Y PATRIMONIO, ¿MATERIAL, INMATERIAL O EVANESCENTE?}

El recorrido previo nos remite a la pregunta que encabeza este apartado, y es que surge un debate explícito acerca de si las transformaciones sociales que tienen que ver con el libro y con la lectura afectan a su consideración cultural. Tradicionalmente y en la actualidad, el valor de las bibliotecas es algo socialmente reconocido. Se ha consensuado que se admire y respete este lugar como referencia de culto y en ella se albergan y conservan incunables y textos de distinta índole. Paradójicamente, la dinámica actual permite editar multitud de libros y estos cada vez tienen una menor cabida en bibliotecas básicamente por una cuestión de espacio. Entonces, progresivamente, este patrimonio material que consideramos mediante los libros que hay en las bibliotecas no queda en entredicho pero sí se plantea el reconocimiento de otro tipo de patrimonio que tenga más que ver con lo inmaterial. La apuntada proliferación de textos digitales en el marco de una cultura audiovisual nos hace plantearnos si esas nuevas modalidades lectoras sobre las que hemos estado reflexionando van a formar parte de lo material o de lo inmaterial. Siendo más extremistas y negativos, también se podría considerar la posibilidad de que este auge de lo digital convirtiese la práctica lectora en algo evanescente por lo que su consideración patrimonial iría decayendo.

En todo caso, desde nuestra perspectiva, la lectura como manifestación que proviene del uso del lenguaje será considerada como patrimonio inmaterial. Como nos indica Asiáin (2014), a partir de las líneas maestras de la UNESCO, el patrimonio cultural inmaterial integraría saberes (conocimiento y modos de hacer enraizados en la vida cotidiana de la comunidades), celebraciones (rituales, fiestas, prácticas de la vida social), formas de expresión (literarias, musicales, plásticas, escénicas, lúdicas...) y lugares (mercados, ferias, santuarios, plazas...). Las transformaciones sociales que tienen que ver con el contexto digital van a provocar un cambio en los usos y en la concepción acerca de qué es leer, pero la percepción cultural, la importancia y la utilidad de la lectura no van a quedar en entredicho. Como hecho asociado a la 
capacidad para pensar y dilucidar que tiene el ser humano, el acto lector le acompaña en su cotidianeidad, le ayuda y le faculta para comprender la realidad que le trasciende. Además, permite que una cualidad humana como la memoria, tenga un importante sustento, pudiendo reflejar en los textos los pensamientos, creencias, sentimientos o inquietudes que tienen las personas.

Al señalar el término evanescente, sí que podemos temer que la lectura como acción que comporta una referencia en papel físico pudiese estar en entredicho; sobre todo, por la evolución social que en un determinado momento, basándose en los aspectos económicos, decidiese prescindir de esa presencia del formato clásico. El hecho de no poder palpar y conservar de manera explícita esos textos sino que estos estuviesen inscritos en la digitalidad, podría hacer pensar en lo liviano del acto lector que sin referente sobre lo que leer, podría verse afectado. Pero, creemos que la lectura trasciende a la materialidad y su evolución a lo largo del tiempo ha propiciado que su vinculación con el ser humano no sea fácilmente sesgable. Por ello, constituye un valioso patrimonio que los educadores deben preservar mediante su labor. En este caso, la perspectiva crítica es altamente relevante, ya que, dotando al alumnado de una autonomía de pensamiento y una capacidad para poder discernir aquello que es importante de lo que no, podremos poner de manifiesto que la lectura es importante para la formación de las personas. Se trata de que, particularmente, el alumnado llegue a la conclusión de lo que la lectura supone en su día a día y en su labor profesional o particular. Solo de ese modo esta podrá tener un reconocimiento social y su valor mantenerse en el espectro patrimonial.

\section{BOOKTRAILERS, BOOKTUBERS, LECTURA EN PANTALLA. INCIDENCIA EDUCATIVA}

La sociedad digital afecta al comportamiento de las personas en su día a día $\mathrm{y}$ en lo que concierne a la lectura también se produce una incidencia que, paulatinamente, tiene una mayor visibilidad. Existen fenómenos vinculados al impacto digital que tienen que ver con la lectura y, sobre los que, inevitablemente, hay que realizar valoraciones. Estas nuevas actuaciones son frecuentes en el devenir cotidiano de la sociedad, por ello, es preciso que establezcamos qué beneficio pueden tener en el acto lector o si por el contrario realmente no lo tienen. Como hemos comentado previamente, la lectura en pantalla es una realidad constatable. Cada vez más personas optan por el uso de dispositivos 
electrónicos en los que poder leer los textos u obras literarias que desean. Este hecho se produce principalmente debido a la comodidad que supone poder desplazar una cantidad ingente de textos en un utensilio que no ocupa tanto espacio. Pero, como hemos reseñado con anterioridad, las evidencias nos muestran que esta lectura en pantalla no mejora la comprensión lectora que se produce cuando se trabaja con un libro físico. Es cierto que todavía están por revelarse los nativos digitales como usuarios constantes de la lectura en pantalla y que serán ellos los que probablemente marquen la pauta sobre el rendimiento de esta utilización.

En la actualidad la convivencia entre lectores tradicionales, residentes digitales y nativos digitales muestra un espectro mezclado en el que sí tenemos clara la diferencia entre los tipos de formato pero, posiblemente, es la influencia de la alfabetización tradicional la que provoca esa diferenciación. El hecho de que el ámbito educativo se haya caracterizado y caracterice por el uso de libros de texto en formato físico, por la recomendación de lecturas en papel, motiva que no pueda haber una medida real acerca del impacto del uso de las pantallas. Será, con el transcurso de los años cuando los usuarios se equiparen en cuanto a formación previa y continua -nos referimos a la alfabetización digital-y podamos calibrar las implicaciones que tiene el cambio de formato en la acción lectora.

Por otra parte, hemos de mencionar en este apartado la aparición de los llamados booktrailers. A modo de equiparación con el ámbito cinematográfico, se ha procedido a generar esta estrategia que tiene como intención la promoción de la lectura, concretamente de una obra literaria concreta. La potencia divulgativa que tiene la red permite contemplar que supone un buen medio para acercar los libros a diferente público y que la existencia del texto sea conocida por multitud de personas; ahora bien, como posible punto débil, se detecta el que ya ocurre con las películas, y es que en ocasiones se facilita demasiada información acerca del contenido del libro y el booktrailer no se convierte en un instrumento que atraiga a la persona lectora sino que en ocasiones la puede disuadir. Ocurre algo similar con el otro concepto o fenómeno que señalamos en esta sección y es que los booktubers son personas que poseen un canal propio en youtube, proporcionando en el mismo su crítica acerca de los libros que están leyendo o han leído. Indicamos que la situación es parecida, ya que, si el booktuber revela demasiada información sobre el texto a la persona que está viendo la emisión, puede provocar que quede disuadida de querer leer ese libro. 
Pese a estas indicaciones que hemos realizado sobre los aspectos que pueden ser no deseables en lo que respecta a los booktubers, los booktrailers o la lectura en pantalla, somos de la opinión referida a que pueden tener una incidencia positiva para la formación de las personas. Así nos lo indican en sus textos tanto García (2016) como Rosal (2016); el hecho que tiene que ver con la difusión es un elemento que favorece al ámbito educativo, ya que, dota de nuevos recursos al profesorado o educadores y, sobre todo, permite que las personas tengan a su disposición títulos y obras que podrán leer. Corresponde al profesorado ser el mediador entre esos textos y el alumnado. En este sentido, la perspectiva crítica será fundamental porque se trata de enseñar a los estudiantes a conocer múltiples recursos y poder seleccionar los mismos con un criterio propio. Un aspecto importante es mostrarles que, aunque tienen la posibilidad de acceder a un universo inmenso de información, ellos tienen que desarrollar la capacidad para saber escoger aquello que está acorde con sus intereses y con su formación académica y personal. Hemos de considerar pues estos recursos o estrategias como algo a añadir al bagaje de instrumentos y cuestiones que los docentes o educadores pueden usar en la formación de personas, siempre teniendo en cuenta la salvedad referida a una utilización crítica de los mismos.

\section{FLUCTUACIÓN DEL TEXTO. TRASVASES Y ACTIVACIÓN DEL PENSAMIENTO}

En la nueva configuración de la lectura hallamos nuevas manifestaciones que afectan de manera notable a la percepción y al moldeamiento del pensamiento, ya que la linealidad no es algo único sino que nuevas muestras se ponen a disposición de las personas. Por ello, podemos indicar que el texto fluctúa y no es algo estático pudiendo mostrarse en diferentes formatos o versiones sin que por esa razón tengamos que alarmarnos. El debate surge siempre ante los cambios que puede sufrir un texto original que no son del agrado de determinados lectores, pero una postura que abogue por la evolución tendrá que entender que si un texto se expande y se versiona con los consecuentes cambios, lo que genera es una nueva producción distinta que enriquece el universo textual. En ningún caso pretende anular el origen sino que versiona el mismo y lo amplía originando nuevas obras que pueden ser o no del agrado de los usuarios. 
Que el texto fluctúe supone concebir que no sea algo estático e implica estar abierto a esa nueva concepción de la lectura sobre la que hablábamos en apartados previos. Y supone una activación del pensamiento, ya que la persona tiene que ser capaz de identificar diferentes historias que, es posible que de forma dinámica, hayan mutado en otros textos o simplemente se hayan fragmentado para formar parte de otras producciones. En este caso, la labor crítica del pensamiento y el pensamiento lateral son claves porque la ausencia de una linealidad constante motiva que haya que detectar detalles que son importantes para entender lo que se muestra.

Un ejemplo interesante que queremos apuntar tiene que ver con un álbum ilustrado que ha obtenido críticas muy positivas y que es usado frecuentemente en el ámbito educativo: El cazo de Lorenzo de Isabelle Carrier. Esta obra literaria tiene una transposición o versión en forma de corto animado realizada por Eric Montchaud que se denomina Le petite casserole d'Anatole. Tras la lectura del álbum y el visionado del corto animado, las opiniones pueden ser diversas. En primer lugar, si ligamos lo expresado en apartados previos con estas dos producciones, tendremos que revisar si en ambas estamos leyendo o no. Desde el punto de vista de la vanguardia y de una visión evolucionada del concepto lector, nosotros en este artículo diremos que ambas son situaciones de lectura, aunque la forma de leer es distinta. Por otra parte, en lo concerniente a la fluctuación del texto, este es un ejemplo relativo a cómo esta se ha producido. El texto original de Isabelle Carrier ha sido transformado y no por ello se ha convertido en mejor o peor. Simplemente se ha tornado en diferente y con ello ha enriquecido el universo textual. Lo ha hecho, ya que a los residentes digitales y amantes de lo audiovisual les parecerá un diseño muy atractivo y entenderán determinadas cuestiones relativas al contenido; y los amantes de la tradición podrán valorar qué se ha hecho a partir del álbum ilustrado original criticando o ensalzando los cambios o variaciones que hayan acontecido.

Otro ejemplo que queremos reseñar que tiene que ver con la fluctuación del texto es la colección de cómics Fábula de Bill Willingham. Está basada en personajes clásicos de los cuentos de hadas y el folclore. La fluctuación de este texto se produce en primer lugar por el hipotexto que suponen los cuentos clásicos y sus personajes, a la par que existe una versión en forma de videojuego denominada The wolf among us desarrollada por Telltale games. Esta transposición supone que el texto transite por dos formatos diferentes permitiendo a la persona que hace uso de los distintos dispositivos enfrentarse a dos maneras diferentes de leer sin que por ello se vea perjudicada su capacidad 
cognitiva. Al contrario, como estamos demandando en esta aportación, la variedad de formatos puede estimular el pensamiento y activar la capacidad crítica para verter opiniones acerca de los componentes del universo textual al que se está enfrentando la persona.

Otro ejemplo paradigmático que acontece en nuestros días y que da muestras de las transformaciones sociales que afectan al ámbito de la lectura podemos hallarlo en la saga Canción de hielo y fuego de George R.R. Martin. La singularidad de la saga y el empuje audiovisual ha motivado que la adaptación televisiva haya superado en desarrollo narrativo a su inspiración que son los cinco libros publicados. Este hecho provoca división de opiniones, ya que los que se aferran a la narrativa basada en textos tradicionales pueden censurar el hecho referido a que se haya continuado una trama ficticia sin tener un referente concluido. Por otra parte, encontramos una visión más positiva en lo que respecta a observar el fenómeno como un enriquecimiento y una creación de un universo textual en el que varias manifestaciones pueden cohabitar sin que por ello, como ocurría en El cazo de Lorenzo, una versión sea mejor o peor que el original.

Desde la visión educativa, consideramos óptima la presencia del trasvase de textos en las manifestaciones culturales, ya que supone estímulo continuo para la activación del pensamiento por parte de las personas que aprenden. Lógicamente, corresponde al guía o mediador la labor concerniente a enseñar a pensar y a saber manejar los múltiples y diferentes recursos con los cuales uno se puede encontrar en el día a día. Hemos mencionado varios ejemplos pero hay muchos más. Citamos una serie de televisión actual, Penny dreadful, creada por John Logan, en la que a lo largo de tres temporadas y veintisiete episodios se nos narran, por ejemplo, los orígenes de personajes literarios como Dorian Gray, Drácula o el Doctor Frankenstein. Estos trasvases culturales suponen un desafío formativo, ya que, hay que saber sacar partido de estos recursos y no considerarlos periféricos y lejanos al mundo académico y lector. En definitiva, dichos ejemplos refuerzan la idea de esta aportación, debemos leer - de formas distintas, mediante formatos narrativos diferentespara pensar y para crecer como personas dentro de un entramado racional y cultural que como seres humanos hemos creado. 


\section{CONCLUSIONES}

Reflexionando acerca de toda la información mostrada y debatida a lo largo de los distintos epígrafes tenemos que generar una serie de ideas clave que sirvan para estructurar los hallazgos que hemos alcanzado y que queremos destacar. El principal tiene que ver con que no podemos anclarnos en el pasado y creer que la lectura se limita a la interacción entre un libro (formato físico) y una persona, sino que la sociedad digital promueve una cultura audiovisual que se entremezcla con la tradición lectora. Coincidiendo con Chartier (2010), el cambio de concepción concerniente a la lectura es un hecho. Con ese punto de partida hemos de analizar los diferentes condicionantes que desde la sociedad se muestran. Y es que la postmodernidad que nos trasciende con unos intereses industriales y un capitalismo explícito es clave para entender qué aproximación se puede realizar al acto lector y cómo puede afectar en el comportamiento o actitudes de las personas hacia la lectura.

Hemos comentado que la interacción entre el texto y la persona junto con su expectativa y bagaje experiencial determinan cómo va a ser la lectura y se convierten en los elementos clave que nos ayudan a entender el concepto. Ese dinamismo que atribuimos a la noción lectora tiene que ir acompañado por la necesidad de inculcar en las personas el espíritu crítico que les permita discernir y opinar acerca de los textos que van a manejar en su día a día, en su labor profesional o en su tiempo de ocio. Ante los nuevos formatos en los que se puede presentar el texto, la facilidad para involucrarse en un pensamiento creativo es importante para poder amoldarse ante una presentación textual que, en muchas ocasiones, no va a ser lineal.

Como novedades que incorporan narraciones hallamos el cine, la televisión (en forma de series), internet (en forma de textos con los que interactuar) o los videojuegos (no tanto los arcade como las aventuras gráficas o los juegos de rol). En todos ellos se produce una presentación textual que difiere de la tradicional pero no por ello pierde contenido, sino que podemos considerar que es otra forma de leer, que requiere el desarrollo de otras destrezas $y$, que complementa la manera tradicional que todos conocemos. Estas transformaciones provocan cambios de concepción en cuanto a la percepción de la lectura, y si bien la concebimos como un bien patrimonial, el asumir la hibridación de formatos es importante para mantener la valoración de ella en nuestra sociedad.

La otra gran conclusión que alcanzamos, además de la que se refiere a la noción de lectura, tiene que ver con el impacto educativo. Como 
hemos mencionado, nuestro objetivo es formar personas con autonomía de pensamiento y capacidad crítica. Por esa razón hemos de aprovechar los recursos que esa sociedad digital y audiovisual nos presenta, procurando ser guías o mediadores para que las personas en formación puedan beneficiarse de esos nuevos formatos o de las estrategias que van asociadas a los mismos. La lectura en pantalla, los booktrailers o los booktubers son aspectos sobre los que hemos reflexionado y, como hemos indicado, se unen a la actividad educativa o formativa para beneficiar la promoción de la lectura. Hacer un uso adecuado de ellos redundará en la delimitación del concepto lector y en su contextualización en el siglo XXI. Ya nos indica Trujillo (2014) en su obra que la institución educativa tiene que incorporar los artefactos digitales para poder adaptarse a los tiempos actuales. Desde una perspectiva más social, Martos y Martos (2014) también reclaman esa reeducación social con la finalidad de integrar el mundo digital con el ámbito académico y formativo.

Por último, la idea que une las dos anteriores y que proyecta la intención de todo el estudio se relaciona con la fluctuación del texto, y cómo asumir ese dinamismo es clave para la formación de la ciudadanía en la época en que vivimos. Así, entender que un texto tendrá transformaciones y va a tener diferentes versiones en formatos narrativos distintos es una realidad social que tiene que ser asumida. Conocer este hecho, educativamente, tiene que ser un acicate para poder activar el pensamiento y para poder llevar el mismo hacia una orientación más creativa. Estas ideas son las que concluyen esta aportación y tratan de insertarla en un contexto de alfabetización digital y de modernidad líquida.

\section{BIBLIOGRAFÍA}

Asiáin, Alfredo. "Lenguaje y patrimonio cultural inmaterial (PCI)". El patrimonio cultural inmaterial: ámbito de la tradición oral y de las particularidades lingüísticas. Coord. Patxi Salaberri. Pamplona: Universidad Pública de Navarra, 2014. 13-33.

Bauman, Zygmunt. Modernidad líquida. México: Fondo de Cultura Económica, 2003.

Chartier, Roger. "Aprender a leer, leer para aprender". Nuevo mundo, mundos nuevos 10 (2010) http://nuevomundo.revues.org/58621. (24/06/2016).

Christensen, Arnfinn. "Paper beats computer screens". SienceNordic (2013) http://sciencenordic. com/paper-beats-computer-screens (24/06/2016).

De Bono, Edward. El Pensamiento Lateral. Barcelona: Paidós, 2006.

Encabo, Eduardo. "Lectura crítica". Diccionario de nuevas formas de lectura y escritura. Coords. Eloy Martos y Mar Campos. Madrid: Santillana, 2013. 371-372. 
García, Gemma. "Booktube. Lectura juvenil por un tubo". Mi biblioteca: la revista del mundo bibliotecario 44 (2016): 58-62.

Giddens, Anthony. Consecuencias de la modernidad. Madrid: Alianza, 1993.

Iser, Wolfang. El acto de leer. Madrid: Taurus, 1987.

Jauss, Hans Robert. Experiencia estética y hermenéutica literaria. Madrid: Taurus, 1977.

Jenkins, Henry. Convergence Culture. La cultura de la convergencia de los medios de comunicación. Barcelona: Paidós, 2008.

López Valero, Amando, Eduardo Encabo e Isabel Jerez Martínez. "Competencia digital y literacidad: nuevos formatos narrativos en el videojuego "Dragon Age: orígenes"". Comunicar: revista científica iberoamericana de comunicación y educación 36 (2011): 165-171.

Lluch, Gemma. "Un nuevo lector, una nueva lectura, unos nuevos formatos". Las lecturas de los jóvenes. Un nuevo lector para un nuevo siglo. Ed. Gemma Lluch. Barcelona: Anthropos, 2010. 7- 38.

Martos, Eloy y Mar Campos. Diccionario de nuevas formas de lectura y escritura. Coords. Madrid: Santillana, 2013.

Martos, Eloy y Alberto Martos. "Artefactos culturales y alfabetización en la era digital: discusiones conceptuales y praxis educativa. Teoría de la educación 26 (1) (2014): 119-135.

Minelli, Janaina, Mar Camacho y Mercè Gisbert. "Explorando la percepción de estudiantes y profesor sobre el libro de texto electrónico en Educación Primaria". Comunicar: Revista científica iberoamericana de comunicación y educación 42 (2014): 87-95.

Robinson, Ken. El elemento: descubrir tu pasión lo cambia todo. Barcelona: Grijalbo, 2009.

Rosal, María. "Écfrasis y fantasía en "El libro de los portales", de Laura Gallego". Signa: Revista de la Asociación Española de Semiótica 25 (2016): 1059-1079.

Solé, Isabel. Estrategias de lectura. Barcelona: Graó, 1992.

Soria, Anna. "Estudio de los efectos del formato hipertextual en la comprensión lectora y la memoria textual en niños de educación primaria”. Educación XX1 18 (1) (2015): 369-390.

Trujillo, Fernando. Artefactos digitales. Una escuela digital para la educación de hoy. Coord. Barcelona: Graó, 2014. 